\title{
Evaluation of driver exposure risk on toxins emitted from exhausts engine in traffic congestion simulated conditions
}

\author{
Maria Skrętowicz ${ }^{1, *}$, Anna Janicka ${ }^{1}$, Radosław Wróbel $^{1}$, and Maciej Zawiślak ${ }^{2}$ \\ ${ }^{1}$ Wroclaw University of Science and Technology, Division of Automotive Engineering, Faculty of \\ Mechanical Engineering, Braci Gierymskich 164, 51-640 Wroclaw
}

\begin{abstract}
The increase in the number of vehicles and better availability of car purchase cause that nowadays people tend to spend more time inside cars. In urban traffic conditions, vehicles moves at low speeds. In addition, traffic lights and high traffic flows cause frequent stops of vehicles and often lead to congestions. The consequence is high amount of exhaust emission and high levels of the concentration of pollutants in the air. In such conditions, pollutants including hydrocarbons from the group of volatile organic compound enter the interior of vehicles with air passing into the cabin. It accumulates mainly in the area of the driver and the passengers heads. In this paper the results of the research of volatile organic compounds concentration inside two different passenger cars in simulated traffic congestion conditions are presented. The study involved vehicles of various ages: new (2011) and old (1999). On the basis of the study the driver exposure inside these vehicles to the impact of volatile organic compounds has been evaluated.
\end{abstract}

\section{Introduction}

The development of automotive industry is very dynamic and results in ever increasing number of cars on the roads. This carries a positive social effect, as it allows quick and comfortable movement from place to place. On the other hand, development of automotive industry causes a lot of dangers for people and environment. The direct result of fuel consumption in internal combustion engines is the emission of harmful fumes into the atmosphere. This is especially true for the cities, where traffic is very intensive and emission of exhaust gases is much higher. High intensity of urban traffic poses immediate threats for all the traffic participants, not only for the drivers, but also for pedestrians (e.g. accidents) $[1,2]$. Exhaust gases introduced into the atmosphere can get into the car cabin via the car ventilation system and cause danger for travellers.

Most of research on air pollution inside the car are focused on the following components of air: particle matter $(\mathrm{PM})$, nitrogen oxides $\left(\mathrm{NO}_{\mathrm{x}}\right)$ and carbon monoxide $(\mathrm{CO})$. Very few studies have been conducted for hydrocarbons (HC), especially for the volatile organic compounds (VOCs). The results of these research indicate also other than the cabin ventilation system sources of VOCs inside the vehicle. Many of them can be formed directly inside the cabin. VOCs can be emitted from the materials used to construct the 
cabin equipment, for example upholstery, glue, gaskets, etc. However, emission of VOCs from these source is a problem mainly for new cars [3-5]. This paper focuses on the amount of VOCs introduced into the interior of vehicles through air ventilating the cabin. Urban traffic is characterized by the formation of congestion, which supports this process. Numerous studies and analysis have shown that the most pollutants inside the car cabin cumulative at the height of the driver's and passenger's head [6]. But a lot of researches focused on the dust getting into the car cabin and on the efficiency of the cabin filters [7-8]. In literature it is hard to find works concerning on the VOCs getting from the ambient air into the passenger car cabin.

The research has been carried out in simulated traffic congestion conditions. Two different passenger cars have been tested: new (2011) and old one (1999). This has allowed to test, which type of car, the new or the old one is more exposed to contaminants entering the car cabin.

\section{Materials and methods}

Two different passenger cars have been tested: a newer Mazda 3 Exclusive+ (2011) and an older one Seat Ibiza (1999). The amount of VOCs getting into cabins of tested cars was measured. In addition, a third car was used: emitting car, positioned in front of the tested vehicle. The emitting car, Opel Corsa C (2001), fulfilling Euro 4 Standards was unchanged throughout the test. The tested cars (Mazda and Seat) had different construction of ventilation system. Table 1 contains parameters of the cars used in the research.

Table 1. Basic technical data of vehicles used in the research.

\begin{tabular}{|c|c|c|c|}
\hline Mark and model & Seat Ibiza & $\begin{array}{c}\text { Mazda 3 } \\
\text { Exclusive+ } \\
\text { Category }\end{array}$ & Opel Corsa C \\
\hline Year of production & 1999 & 2011 & 2001 \\
\hline Fuel & \multicolumn{3}{|c|}{ gasoline } \\
\hline Engine capacity, $\mathrm{cm}^{3}$ & 1390 & 1598 & 973,00 \\
\hline Engine power, $\mathrm{hm}$ & 60 & 105 & 58 \\
\hline
\end{tabular}

Before the right test, background measurements in the tested car have been made. Background measurement was to determine the concentration of VOCs inside the cabin before the tests. After the tests it was possible to calculate the amount of VOCs that has entered the cabin. The distance of $70 \mathrm{~cm}$ between the two cars (emitting and tested) was similar to that encountered in real traffic.

The samples have been collected in two places of the tested vehicle (both for background and proper measurements) outside the vehicle, in the vicinity of the inlet air to the ventilating system and inside the cabin. Location of sampling inside the cabin is a very important element of the tests as it allows to assess the exposure of the driver to contamination present in the cabin air. These samples have been collected in accordance to the European norm ISO/DIS 12219-1:3 [9], which is presented in Figure 1. The location is related to CFD calculation results according to which the highest concentration of pollutants accumulates at the driver's head height. 


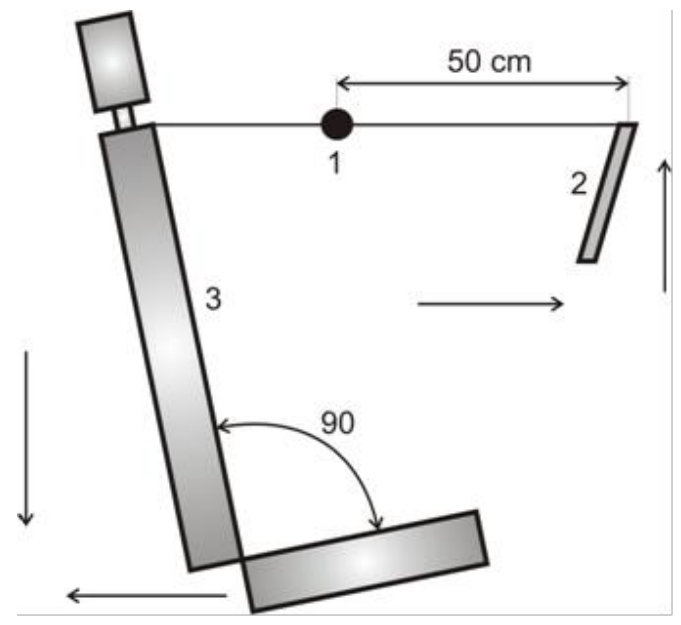

Fig. 1. Location of sample inside the cabin: 1 - sample, 2- steering wheel, 3 - the driver's seat [9].

The samples have been collected using a semi-automatic 2 channel aspirator ASP-2 II, into the tubes with active carbon as a sorbent (SKC_lot 120), outside and inside the vehicle's cabin at the same time. Air flow and time of sampling have been the same in the background and the actual tests. Samples for the determination of background concentration of VOCs inside the cabin were taken immediately before the actual measurement. In table 2 sampling parameters for each car are presented. In figure 2 places of sampling on the example of the Mazda are shown. Four samples was taken from both vehicles: background inside and outside the cabin and right measure inside and outside the cabin. According this, in further considerations short markings were used for the sampling locations: BO - background outside, BI - background inside, MO - measurement outside, MI - measurement inside. Sampling point inside the car cabin was located at the driver's seat at the height of the driver's head and the sampling point outside the cabin was located at wiper, close to the air inlet that ventilates the cabin.

Table 2. Parameters of sampling.

\begin{tabular}{|c|c|c|c|c|}
\cline { 2 - 5 } \multicolumn{1}{c|}{} & \multicolumn{2}{c|}{ SEAT } & \multicolumn{2}{c|}{ MAZDA } \\
\cline { 2 - 5 } \multicolumn{1}{c|}{} & background & right test & background & right test \\
\hline Air flow, $\mathrm{dm}^{3} / \mathrm{h}$ & \multicolumn{4}{c|}{30} \\
\hline Sampling time, $\mathrm{h}$ & 3 & 3 & $2 \mathrm{~h} 55 \mathrm{~min}$ & 3 \\
\hline Air volume, $\mathrm{dm}^{3}$ & 90 & 90 & 86,4 & 89,8 \\
\hline
\end{tabular}
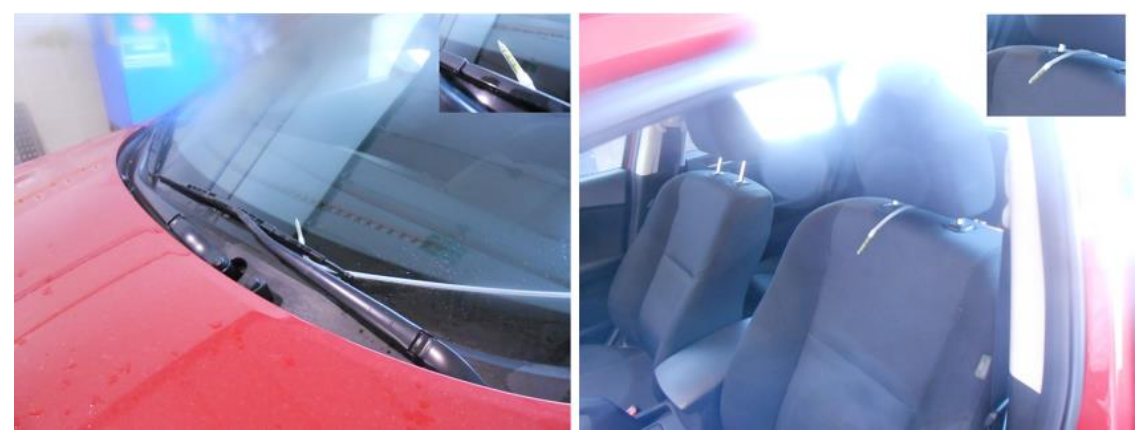

Fig. 2. Location of sample inside and outside the cabin in Mazda. 
The next step was the chemical analysis using the gas chromatography method. It is the best known method to identify and measure concentrations of organic compounds. Prior to the chromatographic analysis, preparation of samples consisting of the desorption of hydrocarbons adsorbed on activated carbon using carbon disulfide as an organic solvent was performed. The prepared samples (Fig. 3) have been analyzed with used a gas chromatograph. The chromatographic analysis has been carried out using a Varian 450-GC chromatograph, equipped with a flame ionization detector (FID), a capillary column type Varian VF-WAXms (30mx0,25mm ID DF: 0,25 $\mu \mathrm{m})$ and an automatic sample feeding. Determination of VOCs concentrations has been carried out under the following conditions:

- oven temperature $-110^{\circ} \mathrm{C}$ during 10 minutes,

- inlet temperature $-250^{\circ} \mathrm{C}$,

- split - 1:20,

- FID temperature $-250^{\circ} \mathrm{C}$,

- carrier gas - helium,

- injection volume $-1 \mu \mathrm{l}$.

a)

b)

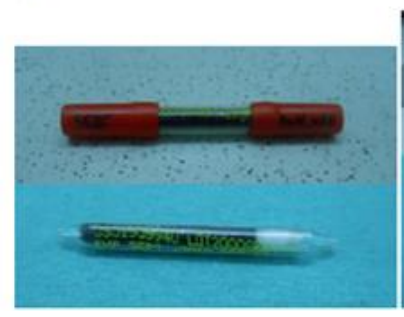

c)

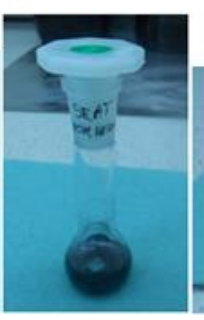

c)

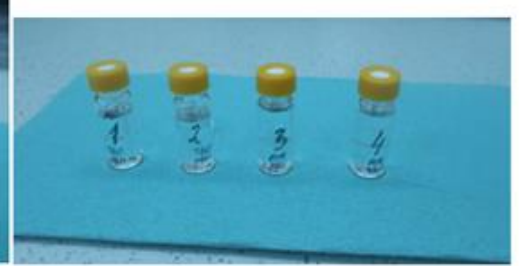

Fig. 3. Samples prepared for gas chromatography analysis: a) sample after gas collection, b) desorption with carbon disulfide as a solvent, c) solution of VOCs prepared for gas chromatography analysis.

The result of each measurement was a set of four samples: outdoor and indoor background, and inside and outside measurement.

\section{Results and discussion}

In Table 3 concentrations of identified VOCs in Mazda and Seat are presented. As it is shown in Table 3, after simulations of traffic congestion, inside the Seat's cabin 11 different VOCs have been identified. Similar situation has taken place inside the Mazda, except for 2-butanol and propylbenzene. What is important, a lot of these compounds have been identified in Mazda also in background tests, before the actual simulations. It means, that Mazda has also another source of VOCs, than exhaust gases contained in the air. The differences in VOCs concentrations between Mazda and Seat registered during the tests are shown in Figure 4. In all samples (BO, BI, MO and $\mathrm{MI}$ ) aggregated concentrations of VOCs have been significantly higher for the Mazda. The high concentration in background outside sample for Mazda could be caused by insufficient ventilation of the hall before start of the sampling. However it does not have impact on the tests inside the cabin. 
Table 3. Identified VOCs concentrations, in $\mathrm{mg} / \mathrm{m}^{3}$ (BO - background outside, BI - background inside, $\mathrm{MO}$ - measure outside, $\mathrm{MI}$ - measure inside).

\section{* Not Detected}

\begin{tabular}{|c|c|c|c|c|c|c|c|c|}
\cline { 2 - 9 } \multicolumn{1}{c|}{} & \multicolumn{4}{c|}{ SEAT } & \multicolumn{4}{c|}{ MAZDA } \\
\cline { 2 - 9 } \multicolumn{1}{c|}{} & BO & BI & MO & MI & BO & BI & MO & MI \\
\hline$n$-pentane & 0.041 & 0.055 & 0.059 & 0.093 & 2.329 & 0.713 & 0.346 & 0.520 \\
\hline 2-propanol & N.D* & N.D* & N.D* & 0.040 & 0.734 & 0.111 & N.D* & 0.081 \\
\hline benzene & N.D* & N.D* & N.D* & 0.022 & N.D* & N.D* & 0.010 & 0.008 \\
\hline 2-butanol & N.D* & N.D* & N.D* & 0.030 & N.D* & N.D* & N.D* & N.D* \\
\hline toluene & N.D* & N.D* & 0.013 & 0.027 & 0.061 & 0.043 & 0.067 & 0.086 \\
\hline ethylbenzene & N.D* & N.D* & N.D* & 0.021 & 0.019 & 0.016 & 0.029 & 0.037 \\
\hline$p$-. $m$-xylene & N.D* & N.D* & N.D* & 0.019 & 0.038 & 0.024 & 0.049 & 0.071 \\
\hline cumene & N.D* & 0.026 & 0.011 & 0.021 & 0.033 & 0.029 & 0.030 & 0.030 \\
\hline$o$-xylene & N.D* & N.D* & N.D* & 0.005 & 0.021 & N.D* & 0.014 & 0.025 \\
\hline propylbenzene & N.D* & N.D* & N.D* & 0.005 & N.D* & N.D* & N.D* & N.D* \\
\hline$p$-cymene & N.D* & 0.041 & 0.029 & 0.037 & 0.038 & 0.042 & 0.039 & 0.038 \\
\hline
\end{tabular}

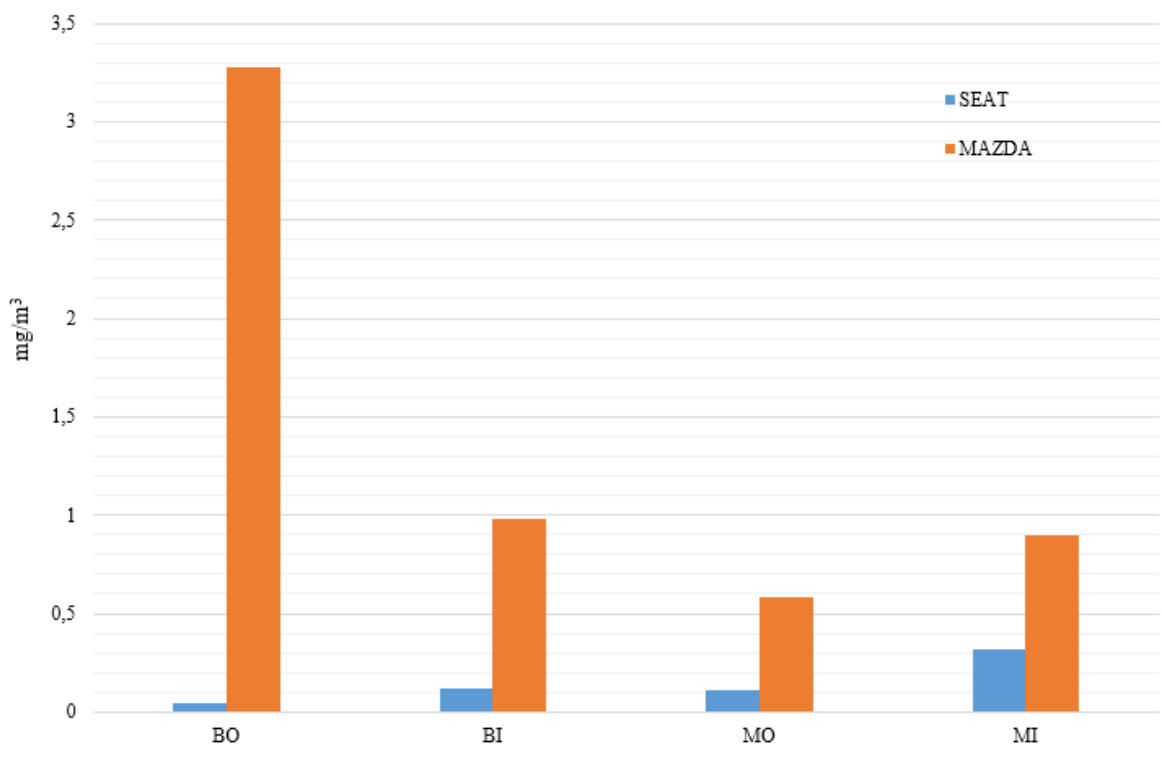

Fig. 4. Concentrations of VOCs measured in tests for Seat and Mazda (BO - background outside, BI - background inside, $\mathrm{MO}$ - measure outside, $\mathrm{MI}$ - measure inside).

To find out how many VOCs have got into the cabin during the simulations, the amount of concentration before simulations measured inside the cabin (background inside, BI) has been subtracted from the concentration measured after the tests (measurement inside, MI). Results of these calculations - the difference between pollutants concentration measured in background and in right test - are presented in Figure 5. 


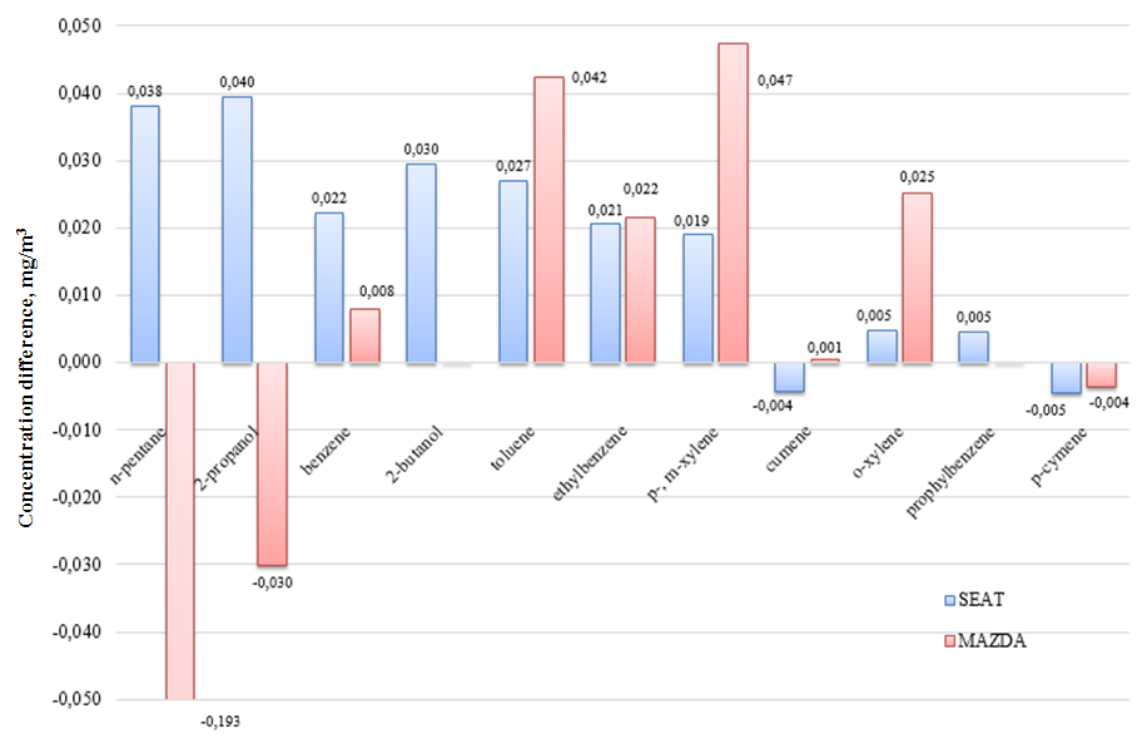

Fig. 5. Concentrations of VOCs getting into the car cabin during the 3-hours simulations for Seat and Mazda.

The negative values indicate a decrease in concentrations in right test relative to background test. As it could be observed, in Mazda, newer vehicle (2011) mainly light VOCs (n-pentane, 2-propanol, 2-butanol) was removed from the cabin and the rest of VOCs' concentrations increased during the test. In the Seat, the older vehicle (1999) concentration of almost all of the analysed VOCs increased. The reason of this might be: the difference in construction of intake channel of fresh air to ventilation the car cabin, difference in materials used to the cabin equipment and difference in way of ventilating the cabin. However, it has been shown that during the traffic congestion, when vehicles are standing one behind the other on the road, the VOCs concentrations could decrease independently from type and vehicle age.

\section{Summary}

Based on this research it has been found out that:

1) the values of measured VOCs concentrations inside the car cabin before (in background) and after 3-hours traffic congestion simulations do not exceed the limits (maximum admissible concentration and short term exposure limit), but it is important to note that, for example benzene is dangerous for human health even in low concentration in long exposure [10].

2) beside n-pentane in Mazda in outside background sample (BO), in all of other cases VOCs concentration values outside are lower than inside the cabin. It means that VOCs accumulated inside the car cabin and do not have a lot of opportunities to escape outside.

3 ) in most cases, VOCs concentration values were higher after simulations than before (in the background). It shows that during congestion pollutants contained in car exhaust fumes enter into the vehicle interior. More VOCs have got into the Seat's cabin that the Mazda's. It could be connected with differences in design and geometry of ventilation system between old and new cars. 
4) in both measurements inside the Mazda (background and right test) higher concentrations of VOCs have been measured than in the Seat. It means that in the case of Mazda VOCs emitted from materials used for interior equipment could be the source of pollution apart from the exhausts getting into the car interior with ambient air.

The results presented in the paper was provided and developed during the 0402/0056/17, POIG.01.04.00-02-154/13 and POIG.04.05.02-00-030/12-00 projects realization.

\section{References}

1. Z. Chłopek, Ecol. Chem. Eng., 6, 8, (1999)

2. Merkisz J., Ekologiczne problemy silników spalinowych. Tom 2 (Wydawnictwo Politechniki Poznańskiej, Poznań, 1999)

3. Grabbs J.S., Corsi R.L., Torres V.M., J. Environ Eng, 126, 10, (2000)

4. Janicka A., Ocena toksyczności mikroatmosfery środowiska wnętrza pojazdu samochodowego (Oficyna Wydawnicza Politechniki Wrocławskiej, Wrocław, 2013)

5. Gołda-Kopek A., Faber J., Łomankiewicz D., Brodzik K., Combustion Engines, 2, 149, (2012)

6. Zawiślak M., Journal of Polish CIMAC, 9, 2 (2014)

7. Tartakovsky L., Baibikov V., Czerwinski J., Gutman M., Kasper M., Popescu D., Veinblat M., Zvirin Y., Atmos Environ, 64 (2013)

8. Abi-Esber L., El-Fadel M., Atmos Environ, 81 (2013)

9. Draft International Standard ISO/DIS 12219-1:2012 Indoor air of road vehicles Whole vehicle test chamber - Specification and method for the determination of volatile organic compounds in cabin interiors (2012)

10. Bernstein J.A., Alexis N., Barnes Ch., Bernstein I.L., Nel A., Peden D., Diaz-Sanchez D., Tarlo S.M., Williams B., J Allergy Clin Immunol, 114, 5 (2004) 